\title{
The reparative capacity of different bioactive dental materials for direct pulp capping
}

\section{Zdolności reparacyjne bioaktywnych materiałów stosowanych w bezpośrednim pokryciu miazgi}

Ehab Mohamed Kamal ${ }^{1, A-E}$, Sameh Mahmoud Nabih²,A,E, Raneem Farouk Obeid ${ }^{3, C, E}$, Mohamed Ayad Abdelhameed ${ }^{4, C}$

\author{
${ }^{1}$ Faculty of Dentistry, Al-Azhar University, Cairo, Egypt \\ ${ }^{2}$ Department of Operative Dentistry, Al-Azhar University, Cairo, Egypt \\ ${ }^{3}$ Department of Oral Biology, Future University in Egypt, New Cairo, Egypt \\ ${ }^{4}$ Department of Veterinary Surgery, Cairo University, Egypt \\ A - research concept and design; $\mathrm{B}$ - collection and/or assembly of data; $\mathrm{C}$ - data analysis and interpretation; \\ $D$ - writing the article; $E$ - critical revision of the article; $F$ - final approval of the article
}

Address for correspondence

Ehab Mohamed Kamal

E-mail:dr.ehabkamal@ymail.com

Funding sources

None declared

Conflict of interest

None declared

Received on March 3, 2018 Reviewed on March 29, 2018 Accepted on April 21, 2018

DOI

$10.17219 / \mathrm{dmp} / 90257$

Copyright

() 2018 by Wroclaw Medical University

and Polish Dental Society

This is an article distributed under the terms of the

Creative Commons Attribution Non-Commercial License

(http://creativecommons.org/licenses/by-nc-nd/4.0/)

\section{Abstract}

Background. Maintaining pulp vitality is a major objective in restorative dentistry. Direct pulp capping (DPC) is considered a way to enhance pulp healing and induce reparative dentin. In the present study, 3 capping materials were used and compared in terms of promoting pulp tissue healing after mechanical exposure.

Objectives. The aim of the study was to evaluate the reparative capacity of Biodentine ${ }^{\mathrm{TM}}(\mathrm{BD})$, TheraCa ${ }^{\circledR} \mathrm{LC}$ and TotalFill ${ }^{\circledR}$ as DPC materials and to assess dentin bridge formation.

Material and methods. The experiment required 3 groups (1-week group, 1-month group and 3-months group), each consisting of 24 fresh human premolars extracted for orthodontic reasons. A cavity was prepared on the buccal surface of each tooth and the pulp tissue was penetrated to a depth of approx. $1.0 \mathrm{~mm}$. After exposure, hemostasis was obtained and the pulp-capping agents BD, TheraCal LC and TotalFill were applied. A final restoration with GC Fuj IX GP Fast (GC Corporation, Tokyo, Japan) was applied to each tooth to ensure an adequate coronal seal. Tissue samples were collected at 1 week, 1 month and 3 months. The samples were demineralized, sectioned, stained, and histologically graded.

Results. There was a statistically significant difference between TheraCal $L C$ and both BD and TotalFill in terms of pulpal inflammation during the 3 capping periods, while BD and TotalFill showed comparable results, with no statistically significant difference between their results in the 3 capping periods.

Conclusions. TotalFill, a newly developed pulp-capping material, offers results comparable to BD in addition to its advantageous handling properties. Although TheraCal LC contains resin ingredients, given proper curing, it seems to be a successful material for DPC and offers superior handling properties.

Key words: pulp vitality, pulp capping, bioactive dental materials

Słowa kluczowe: ̇̇ywotność miazgi, pokrycie miazgi, bioaktywne materiały stomatologiczne 
Maintaining pulp vitality is a major objective in restorative dentistry. Vital pulp therapy aims to maintain the viability of the dental pulp in addition to provoking the remaining pulpal tissue to regenerate the dental-pulp complex. ${ }^{1}$ Direct pulp capping (DPC) is considered a way to enhance pulp healing and induce reparative dentin. Studies on capping materials have been undertaken by many clinicians and researchers, as selection of appropriate capping material is the key to a good treatment outcome. ${ }^{2}$ Calcium hydroxide $\left(\mathrm{Ca}(\mathrm{OH})_{2}\right)$ has been considered the material of choice (the gold standard) for DPC for several decades, but many studies have reported that the strong alkaline nature of the material may induce necrosis of the pulp. ${ }^{3}$ Therefore, mineral trioxide aggregate (MTA) has been used as an alternative to $\mathrm{Ca}(\mathrm{OH})_{2}$ in dentistry. ${ }^{4}$ The advantages of MTA over $\mathrm{Ca}(\mathrm{OH})_{2}$ are its lower degradation potential, enhanced mechanical strength, better marginal adaptation, and sealing ability. ${ }^{5}$ However, MTA still has some drawbacks, such as a prolonged setting time and a sandy consistency, which make the handling of this material difficult. ${ }^{6}$ Recently, reports have been published about bioactive molecules like Biodentine ${ }^{\mathrm{TM}}(\mathrm{BD})$, inducing dentin bridge formation on exposed pulp tissues in experimental animals. ${ }^{7}$ The main advantages of BD over MTA include its ease of handling, greater viscosity, faster setting time, and improved physical properties. ${ }^{8}$ A new bioceramic material (TotalFill ${ }^{\circledR}$ ) has recently been introduced on the market as a new hydraulic material with several applications as pulp capping. ${ }^{9}$ However, unlike MTA, this material does not contain Portland cement, and hydraulic calcium zirconia is included as a radioopacifying agent. ${ }^{10}$ The composition of this new bioceramic material seems promising in many aspects, such as its high mechanical bond strength, fast setting time and lack of discoloration; and since it is premixed, it could be a possible alternative to ordinary MTA. ${ }^{11}$ It therefore seems worthwhile to investigate the reparative effects of these new bioactive dental materials as DPC agents over different observation periods (1 week, 1 month and 3 months), focusing on the dental pulp response and reparative dentin formation.

\section{Material and methods}

\section{Sample preparation}

A total of 72 fresh human premolars (extracted for orthodontic reasons) were used in this study after being examined clinically and radiographically to exclude teeth with caries and periapical pathologies. The teeth were washed under running tap water to remove blood and debris. The apical $3 \mathrm{~mm}$ of the tooth root was cut perpendicularly to the long axis of the tooth using a fissure burr with a high-speed hand-piece (W\&H Impex Inc., Bürmoos, Australia). The teeth were then exposed to ultraviolet light for $20 \mathrm{~min}$ in a biological safety cabinet (SterilGARD III Advance; The Baker Co., Sanford, USA) to ensure decontamination. ${ }^{12}$ The teeth were then transferred to 12-well cell culture plates (Falcon; Becton Dickinson, Franklin Lakes, USA), each tooth in a separate well containing Dulbecco's Modified Eagle Medium (DMEM) supplemented with $300 \mathrm{IU} / \mathrm{mL}$ penicillin, $300 \mu \mathrm{g} / \mathrm{mL}$ streptomycin and $0.75 \mu \mathrm{g} / \mathrm{mL}$ amphotericin per well, and stored for $2 \mathrm{~h}$ at $4^{\circ} \mathrm{C}$ to preserve pulp vitality. ${ }^{13}$

\section{The design of the study}

The samples were randomly divided into 3 main groups according to the capping duration $(\mathrm{n}=24)$ : group 1 (1 week), group 2 (1 month) and group 3 (3 months). Each main group was subdivided into 3 subgroups according to the capping material $(n=8)$ : in subgroup A the exposed pulps were directly capped with BD, while in subgroups $B$ and $C$ the exposed pulps were directly capped with TheraCal $^{\circledR}$ LC and TotalFill ${ }^{\circledR}$, respectively.

\section{Cavity preparation and mechanical pulp exposure}

Standard class V cavities were prepared on the cervical third of the buccal surface of the teeth, approx. $1 \mathrm{~mm}$ coronally to the gingival margin, using a size 3 diamond round stone (MANI Inc., Utsunomiya, Japan) with a high-speed hand-piece (W\&H Impex Inc., Bürmoos, Australia). A modified metal band with a central window was used to standardize the prepared cavities to $3 \mathrm{~mm} \pm 0.5 \mathrm{~mm}$ mesiodistally and $2 \mathrm{~mm} \pm 0.5 \mathrm{~mm}$ occlussogingivally. Copious amount of a coolant from the high-speed hand-piece was used to avoid overheating; each burr was used to prepare 4 cavities. The drilling was maintained until the pulp shadow appeared; this was assisted by means of $\times 4$ magnifying eye loupes (Univet, Rezzato, Italy). A sterile sharp probe was then used to mechanically induce pulp exposure in the center of the cavity. ${ }^{14}$ Diluted sodium hypochlorite (NaOCL) solution (1:1) was applied using a syringe to disinfect the area and to stop any hemorrhage that might have occurred; this was followed by drying with a dry sterile cotton pellet until physiological homeostasis occurred. ${ }^{15}$

\section{Application of the pulp-capping material}

All 3 of the experimental capping materials were mixed according to the manufacturers' instructions and applied to the teeth in the appropriate subgroups. 


\section{Application of the restorative material}

Fuji II LC glass ionomer capsules (GC Corporation, Tokyo, Japan) were used for coronal restoration in this study. In accordance with the manufacturers' instructions, each capsule was first activated by depressing the button on the bottom, and then placed in a RotoMix ${ }^{\mathrm{TM}}$ high-speed amalgamator (3M ESPE Gulf, Dubai, UAE) at approx. 4,300 rpm for $10 \mathrm{~s}^{16}$ The mixed capsule was immediately removed from the amalgamator, placed in a glass ionomer applicator and injected into the cavity.

\section{Hosting period}

The crowns were fixed to a metallic wire with a sealant (Embrace ${ }^{\circledR}$; Pulpdent, Watertown, USA). The wire was suspended on 2 adjacent plates. The apical part of each tooth was dipped in $4 \mathrm{~mL}$ of culture medium without touching the bottom of the culture wells in order to facilitate the diffusion of the medium through the apical part without any direct contact with the restorative material. ${ }^{17}$ The culture medium was changed every day.

\section{Histopathological evaluation}

The histopathological evaluation was based on the International Organization for Standardization (ISO) 7405 criteria. ${ }^{18}$ Inflammatory reactions were graded following the scoring system described in Table $1 .^{19}$

Table 1. Inflammatory reaction scoring system

\begin{tabular}{|l|l|}
\hline Scoring & \multicolumn{1}{c|}{ Description } \\
\hline 0 & $\begin{array}{l}\text { Normal tissue with no or few scattered inflammatory cells } \\
\text { present in the pulp area corresponding to pulp exposure }\end{array}$ \\
1 & $\begin{array}{l}\text { Mild inflammatory cell infiltrate with polymorphonuclear } \\
\text { or mononuclear leukocytes }\end{array}$ \\
2 & $\begin{array}{l}\text { Moderate inflammatory cell infiltrate involving the coronal } \\
\text { pulp } \\
3\end{array}$ \\
& $\begin{array}{l}\text { Severe inflammatory cell infiltrate involving the coronal } \\
\text { pulp or characterizing abscess }\end{array}$ \\
\hline
\end{tabular}

\section{Statistical analysis}

The statistical analysis was carried out using SPSS v. 17 software (SPSS Inc., Chicago, USA). A two-way analysis of variance (ANOVA) was used to test the effects of the materials, time intervals and their interactions on dentin thickness. A one-way ANOVA was used to test the effects of the time intervals for each material, as well as the effects of the materials within each time interval on dentin bridge thickness. A t-test was used to study the changes over time in each group. The significance level was set at $\mathrm{p} \leq 0.05$.

\section{Results}

\section{Effect of capping material on inflammatory score}

The histological sections presenting the normal architecture of pulp tissue consisted of delicate and loose connective tissue. A single layer of peripheral odontoblasts lining the peripheral part of the pulp could be seen separating the loose connective tissue of the pulp from the predentin. This was followed by the cell-free zone and then the cell-rich zone with high densities of fibroblasts. Numerous blood capillaries with red blood cells were also detected (Fig. 1).

The results for group 1 (capping duration: 1 week; Fig. 2) showed that there was a statistically significant difference between the BD subgroup and the TheraCal LC subgroup. However, there was no statistically significant difference between the BD and TotalFill subgroups. In group 2 (capping duration: 1 month; Fig. 3), there was a statistically significant difference between the inflammatory scores of the BD subgroup and of the TheraCal LC subgroup. However, there was no statistically significant difference between the BD and TotalFill subgroups. In group 3 (capping duration: 3 months; Fig. 4) there was a statistically significant difference between the BD subgroup and the TheraCal LC subgroup. However, there was no statistically significant difference between the BD and TotalFill subgroups.

\section{Effect of capping material on the dentin bridge thickness}

The two-way ANOVA showed that both the capping material and the capping duration had statistically significant effects on the dentin bridge thickness. The interaction between the 2 independent variables (capping material and capping duration) had a statistically significant effect on the dentin bridge thickness (Table 2, Fig. 5).

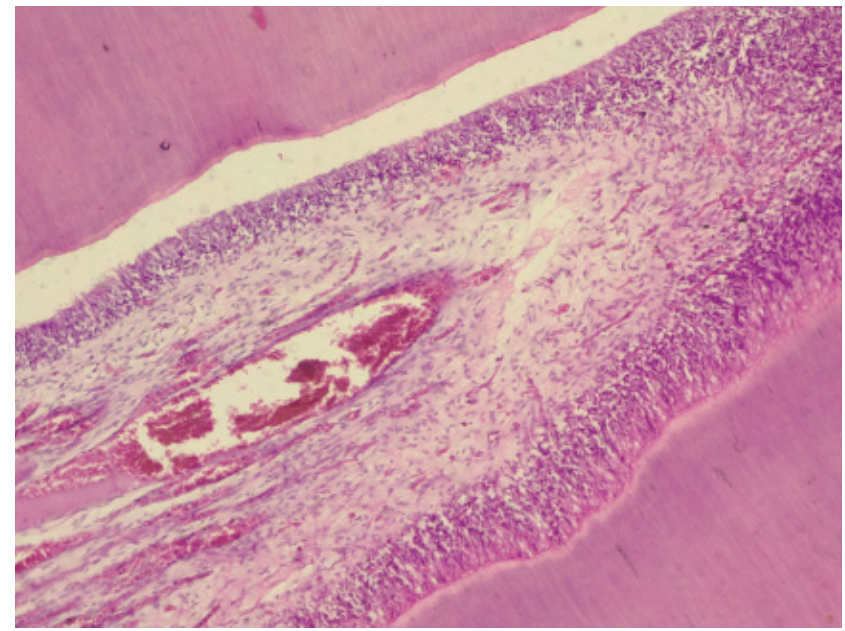

Fig. 1. A photomicrograph of normal pulp hematoxylin and eosin stain (H\&E), (×40 magnification) 

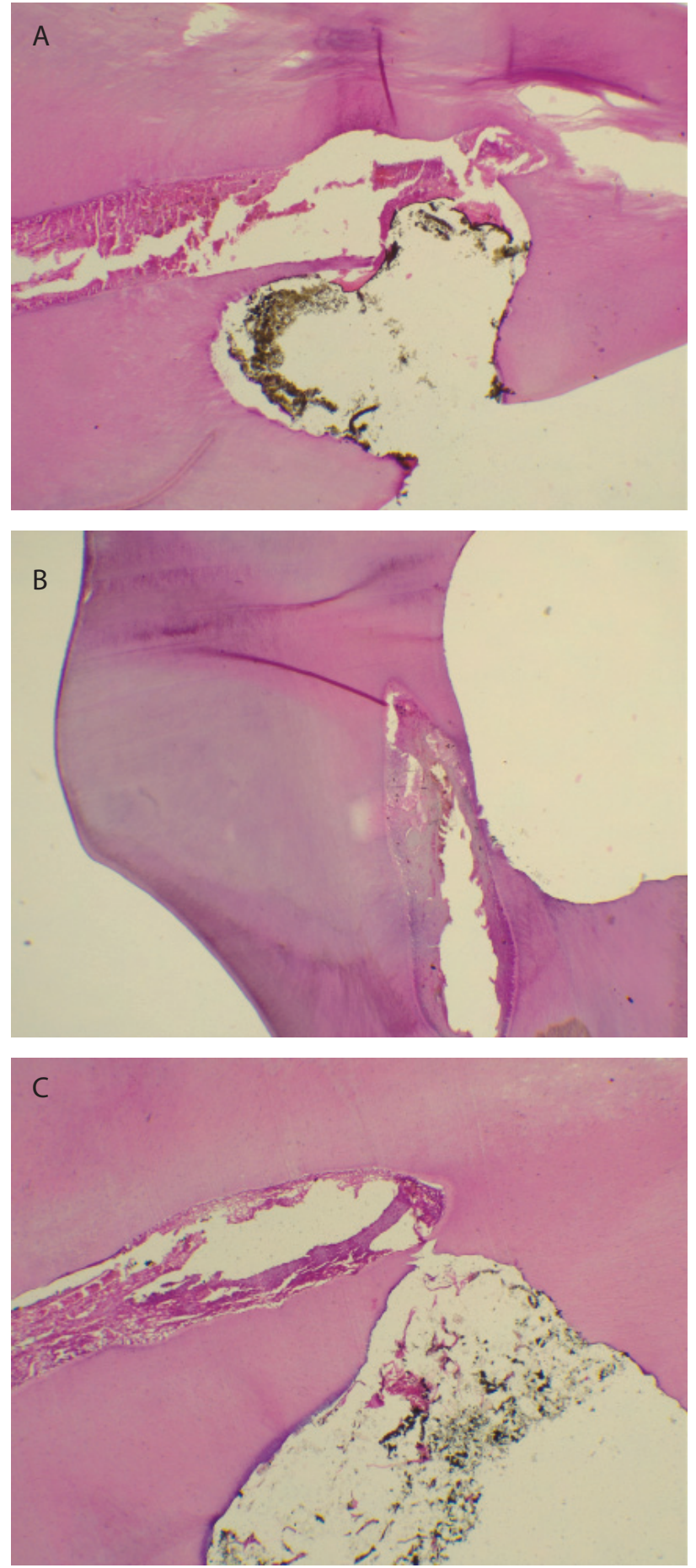

Fig. 2. A photomicrograph hematoxylin and eosin stain (H\&E), ( $\times 40$ magnification) after 1 week, showing mild inflammatory cells in the Biodentine ${ }^{\mathrm{TM}}$ (A) and TotalFill (C) subgroups, and moderate to severe inflammation in the TheraCal LC subgroup (B)
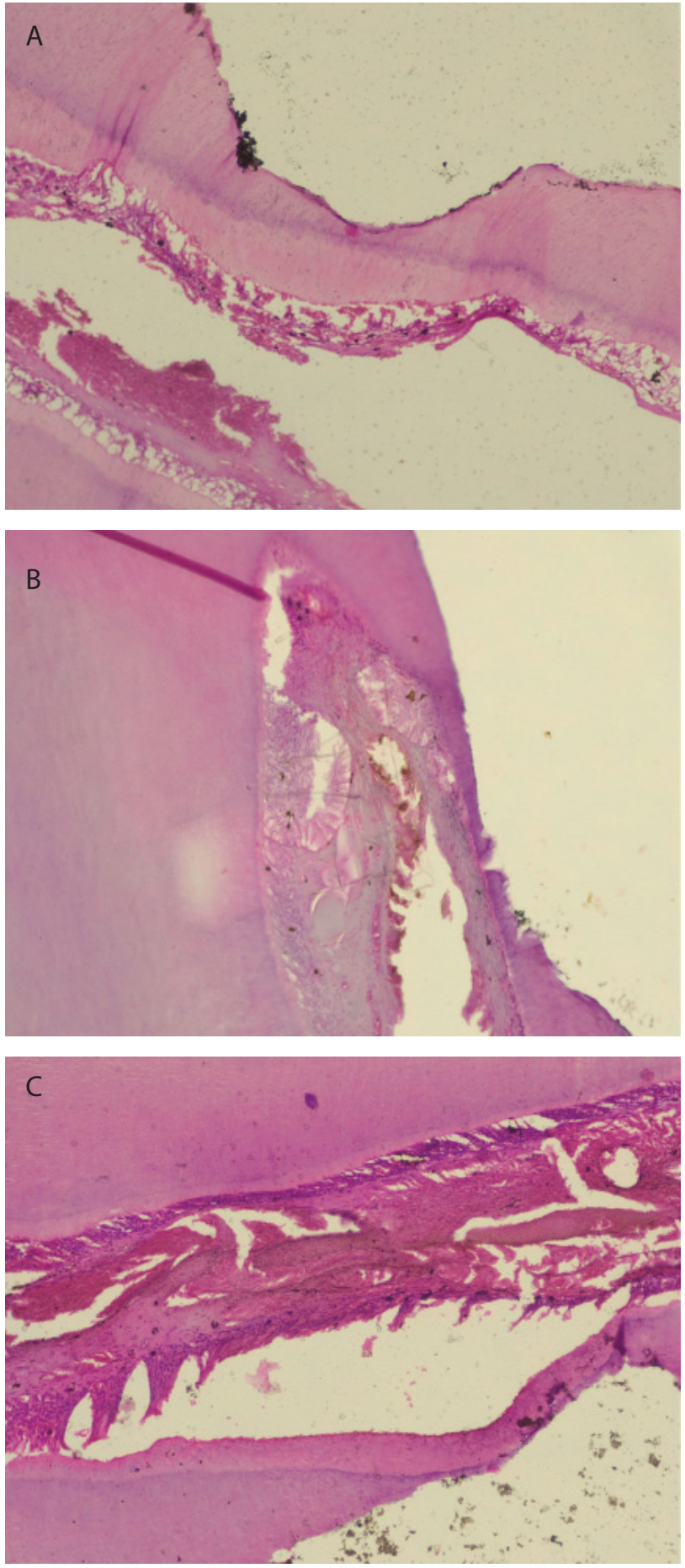

Fig. 3. A photomicrograph hematoxylin and eosin stain (H\&E), ( $(100$ magnification) after 1 month, showing a very thin bridge of dentin, and presenting osteodentin with osteocytes and evidence of newly calcified matrix formation in both the Biodentine ${ }^{\mathrm{TM}}$ and TotalFill subgroups (A\&C). The TheraCal LC subgroup (B) shows a direct transition from a necrotic inflammatory odontoblastic layer to a multilayer of vital odontoblasts

Table 2. Descriptive statistics and test of significance for the effects of capping materials on dentin bridge thickness within the different capping durations

\begin{tabular}{|c|c|c|c|c|c|c|c|c|c|}
\hline \multirow{2}{*}{ Material } & \multicolumn{3}{|c|}{1 week } & \multicolumn{3}{|c|}{1 month } & \multicolumn{3}{|c|}{3 months } \\
\hline & mean & SD & DT & mean & SD & DT & mean & SD & DT \\
\hline Biodentine $^{T M}$ & 0.00 & 0.00 & a & 0.180 & 0.204 & a & 0.520 & 0.294 & a \\
\hline TheraCal LC & 0.00 & 0.00 & $a b$ & 0.078 & 0.113 & $a b$ & 0.159 & 0.207 & $a b$ \\
\hline TotalFill & 0.00 & 0.00 & a & 0.168 & 0.106 & $a$ & 0.347 & 0.276 & a \\
\hline
\end{tabular}

SD - standard deviation; DT - Duncan's multiple range test for the effect of time. Means with the same letter within each column and capping duration are not significantly different at $p=0.05$. 


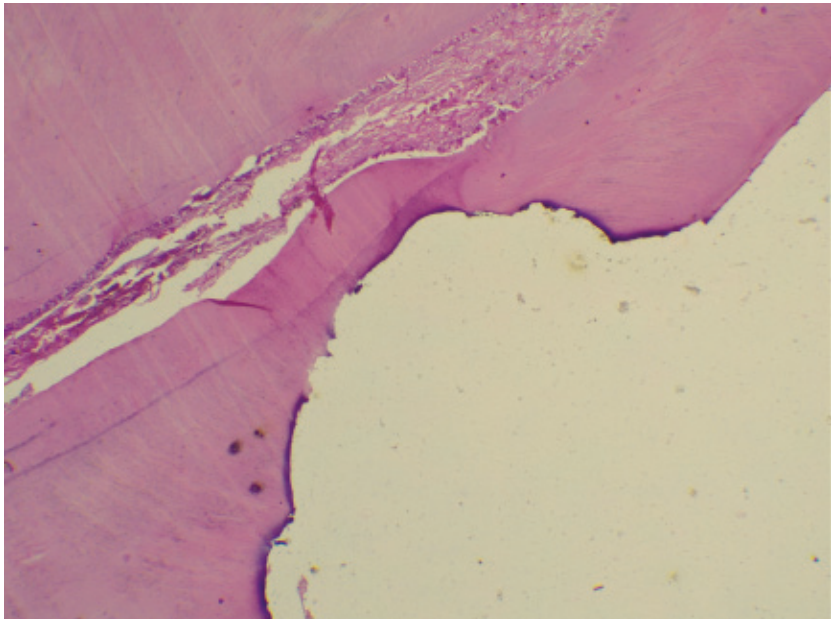

Fig. 4. A photomicrograph hematoxylin and eosin stain (H\&E), ( $\times 40$ magnification) after 3 months, showing dilated congested blood vessels and a bridge of hard tissue formation in both the Biodentine ${ }^{T M} \&$ TotalFill subgroups (A \& C). The TheraCal LC subgroup (B) shows dilated congested blood vessels and a thin bridge of hard tissue formation

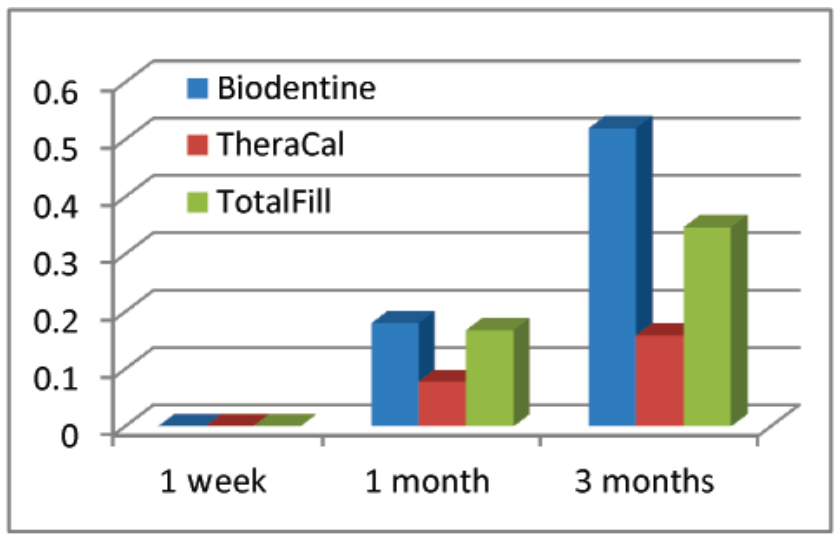

Fig. 5. Mean dentin bridge thickness for the 3 different materials within each capping duration

\section{Discussion}

Traumatized dental pulp cells possess the ability to differentiate into a specific cell lineage, forming tubular dentin in the absence of normal developmental conditions. ${ }^{19}$ Pulp-capping techniques involve direct application of material over the exposed pulp for the immediate induction of cytological and functional odontoblast-like cell differentiation to initiate the formation of reparative dentin at the site of injury. ${ }^{3}$ The entire tooth culture model provides a useful tool to predict the biocompatibility of dental materials. This model allows the early steps of dentine-pulp regeneration and pulp cell behavior to be investigated after applying pulp-capping materials. It reproduces the clinical situation for pulpal exposure in a whole-tooth environment, reducing the use of animal experiments before studies on humans. ${ }^{13}$

In our study, pulpal exposure was performed mechanically with a probe. Although it has been reported that this approach pushes dentin fragments into the pulp, it was found that these fragments seemed to induce an inflammatory pulpal response. ${ }^{14}$ Three capping durations were selected. The 1-week period seemed to show the primary acute response of the tissues. In the 1-month period the cessation of the inflammatory phase and tissue organization was observed in some groups. The 3-month period was essential for a final assessment of the procedure. ${ }^{20}$

The histopathological results for the 1-week period for all 3 capping materials showed destruction of the odontoblastic layer with loss of the normal architecture of the connective tissue stroma, accompanied by inflammatory cells, dilated blood vessels and areas of edema. The general inflammatory pulpal response could be attributed to traumatic injury to the pulp tissue by the mechanical exposure and compression during the capping procedure. Mild to moderate chronic inflammation was found for all the DPC materials, except for TheraCal LC, with which $25 \%$ of the specimens showed severe inflammation. This was in agreement with other studies, which posited that the high percentage of severe inflammation reported with TheraCal LC may be caused by the fact that TheraCal LC contains resinous bisphenol A-glycidyl methacrylate, hydroxyethyl methacrylate and urethane dimethacrylate monomers. ${ }^{21,22}$ If unpolymerized, the free monomers can diffuse through dentin and reach the underlying pulp, where they can exert their toxic effects. Chen and Suh, on the other hand, suggested that light curable resin modified calcium silicates, such as TheraCal LC, have less cytotoxicity and better or comparable clinical outcomes during the $1^{\text {st }}$ week of DPC. ${ }^{23}$

For the 1-month capping period, there was no significant difference in the inflammatory score results between the BD and TotalFill subgroups. This may be attributed to the material properties: as TotalFill creates hydroxyapatite-like precipitates, an alkaline $\mathrm{pH}$ comparable to BD is produced, and $\mathrm{Ca}^{2+}$ is also released, which could be conducive to hard-tissue deposition. The histopathological results for the TheraCal LC subgroup for the 1-month period showed disorganization of the pulp tissue with multiple vacuolations. Moderate to massive inflammation around was seen, and the pulp tissue showed evidence of newly calcified matrix formation. A significant difference could be seen between this subgroup and both the BD and TotalFill subgroups. These findings coincided with those of Jeanneau et al. ${ }^{24}$

The histopathological results for the 3-month capping duration showed restoration of the normal architecture, dentin bridge sealing the exposure site and no to mild chronic inflammation in all 3 subgroups. There was no significant difference between the $\mathrm{BD}$ and TotalFill results, which coincided with those of Parirokh et al., who demonstrated a dentin bridge thickness of $0.25 \mathrm{~mm}$ and no inflammatory pulpal response. ${ }^{25}$ This lack of significant difference could be due to multiple reasons; both materials are biocompatible, bioactive, similar in sealing ability, and have similar antibacterial efficacy. ${ }^{9,26}$ 
In addition, a significant difference may have been achieved if the evaluation period had been extended or if the sample size had been increased per group.

On the other hand, although TheraCal LC results showed dentin bridge formation with mild chronic inflammation, there was a significant difference between the TheraCal LC subgroup and both the BD and TotalFill subgroups in terms of dentin bridge thickness and inflammatory score, which may be attributed to the hydration properties of TheraCal LC. The hydration of TheraCal LC depends on the fluid uptake through the resin matrix from the environment. The high calcium ion release of TheraCal LC was demonstrated in vitro when the material was stored in a solution where the fluid uptake could occur unimpeded. ${ }^{27}$ In the current study there was not enough moisture in the pulp-capping conditions to allow proper hydration of the tricalcium silicate in TheraCal LC, even when it was in contact with several milliliters of solution.

\section{Conclusions}

TotalFill, a newly developed pulp-capping material, offers results comparable to BD in addition to its advantageous handling properties. Although TheraCal LC contains resin ingredients, given proper curing, it seems to be a successful material for DPC and offers superior handling properties.

\section{References}

1. Aguilar $P$, Linsuwanont $P$. Vital pulp therapy in vital permanent teeth with cariously exposed pulp: A systematic review. J Endod. 2011;37:581-587.

2. Ji YM, Jeon SH, Park JY, Chung JH, Choung YH, Choung PH. Dental stem cell therapy with calcium hydroxide in dental pulp capping. Tissue Eng Part A. 2010;16:1823-1833.

3. Hilton TJ. Keys to clinical success with pulp capping: A review of the literature. Oper Dent. 2009;34:615-625.

4. Holland R, de Souza V, Nery MJ, Otoboni Filho JA, Bernabe PF, Dezan $\mathrm{E}$. Reaction of dogs' teeth to root canal filling with mineral trioxide aggregate or a glass ionomer sealer. J Endod. 1999;25:728-730.

5. Dammaschke T, Stratmann U, Wolff P, Sagheri D, Schafer E. Direct pulp capping with mineral trioxide aggregate: An immunohistologic comparison with calcium hydroxide in rodents. J Endod. 2010;36:814-819.

6. Wongkornchaowalit N, Lertchirakarn V. Setting time and flowability of accelerated Portland cement mixed with polycarboxylate superplasticizer. J Endod. 2011;37:387-389.

7. Malkondu O, Karapinar Kazandag M, Kazazoglu E. A review on Biodentine, a contemporary dentine replacement and repair material. Biomed Res Int. 2014;2014:160951. doi: 10.1155/2014/160951

8. Ishizaki NT, Matsumoto K, Kimura Y, Wang X, Yamashita A. Histopathological study of dental pulp tissue capped with enamel matrix derivative. J Endod. 2003;29:176-179.

9. Souza LC, Yadlapati M, Dorn SO, Silva R, Letra A. Analysis of radiopacity, $\mathrm{pH}$ and cytotoxicity of a new bioceramic material. J Appl Oral Sci. 2015;23:383-389.

10. Kang SH, Shin YS, Lee HS, et al. Color changes of teeth after treatment with various mineral trioxide aggregate-based materials: An ex vivo study. J Endod. 2015;41:737-741.

11. Liu S, Wang S, Dong Y. Evaluation of a bioceramic as a pulp capping agent in vitro and in vivo. J Endod. 2015;41:652-657.
12. White JM, Goodis HE, Marshall SJ, Marshall GW. Sterilization of teeth by gamma radiation. J Dent Res. 1994;73:1560-1567.

13. Tecles $\mathrm{O}$, Laurent $\mathrm{P}$, Aubut $\mathrm{V}$, About I. Human tooth culture: A study model for reparative dentinogenesis and direct pulp capping materials biocompatibility. J Biomed Mater Res B Appl Biomater. 2008;85:180-187.

14. Ford TR, Torabinejad M, Abedi HR, Bakland LK, Kariyawasam SP. Using mineral trioxide aggregate as a pulp-capping material. J Am Dent Assoc. 1996;127:1491-1494.

15. Parolia A, Kundabala M, Rao NN, et al. A comparative histological analysis of human pulp following direct pulp capping with Propolis, mineral trioxide aggregate and Dycal. Aust Dent J. 2010;55:59-64.

16. Suhasini K, Madhusudhana K, Suneelkumar C, Lavanya A, Chandrababu KS, Kumar PD. Clinical performance of Class I nanohybrid composite restorations with resin-modified glass-ionomer liner and flowable composite liner: A randomized clinical trial. J Conserv Dent. 2016;19:510-515.

17. Laurent $\mathrm{P}$, Camps J, About I. Biodentine ${ }^{\mathrm{TM}}$ induces TGF-beta1 release from human pulp cells and early dental pulp mineralization. Int Endod J. 2012;45:439-448.

18. Schmalz G, Galler KM. Biocompatibility of biomaterials: Lessons learned and considerations for the design of novel materials. Dent Mater. 2017;33:382-393.

19. Koike T, Polan MA, Izumikawa M, Saito T. Induction of reparative dentin formation on exposed dental pulp by dentin phosphophoryn/collagen composite. Biomed Res Int. 2014;2014:745139. doi: 10.1155/2014/745139

20. Saleh R, Nagi S, Ezzat M, Ibrahim MZ. In-vivo assessment of dentin bridge formation after using MTA and experimental propolis paste as direct pulp capping material. Res J Pharm Biol Chem Sci. 2016;7:1244-1250.

21. Gerzina TM, Hume WR. Diffusion of monomers from bonding resin-resin composite combinations through dentine in vitro. J Dent. 1996;24:125-128.

22. Hume WR, Gerzina TM. Bioavailability of components of resinbased materials which are applied to teeth. Crit Rev Oral Biol Med. 1996;7:172-179.

23. Chen L, Suh BI. Cytotoxicity and biocompatibility of resin-free and resin-modified direct pulp capping materials: A state-of-the-art review. Dent Mater J. 2017;36:1-7.

24. Jeanneau C, Laurent P, Rombouts $C$, Giraud T, About I. Light-cured tricalcium silicate toxicity to the dental pulp. J Endod. 2017;43:2074-2080.

25. Parirokh M, Torabinejad M, Dummer PMH. Mineral trioxide aggregate and other bioactive endodontic cements: An updated overview. Part I: Vital pulp therapy. Int Endod J. 2018;51:177-205.

26. Material Safety Data Sheet. 2018. Brasseler USA ${ }^{\circledR}$ Web site. https:// brasselerusadental.com/education-resource/safety-data-sheets/. Accessed March 6, 2017.

27. Camilleri J, Laurent $P$, About I. Hydration of Biodentine, TheraCal ${ }^{\circledR} L C$, and a prototype tricalcium silicate-based dentin replacement material after pulp capping in entire tooth cultures. J Endod. 2014;40:1846-1854. 